The International Journal of Indian Psychology: Volume: 01 | Issue: 04 | ISSN 2348-5396

\title{
Adjustment, emotional control and perceived loneliness among adolescents
}

\author{
Anu Agarwal*
}

\section{INTRODUCTION}

Adjustment is the behavioral process by which humans and other animals maintain equilibrium among their various needs or between their needs and the obstacles of their environments. A sequence of adjustment begins when a need is felt and ends when it is satisfied. Hungry people, for example, are stimulated by their physiological state to seek food. When they eat, they reduce the stimulating condition that impelled them to activity, and they are thereby adjusted to this particular need. In general, the adjustment process involves four parts: (1) a need or motive in the form of a strong persistent stimulus, (2) the thwarting or no fulfillment of this need, (3) varied activity, or exploratory behavior accompanied by problem solving, and (4) some response that removes or at least reduces the initiating stimulus and completes the adjustment. Social and cultural adjustments are similar to physiological adjustments. People strive to be comfortable in their surroundings and to have their psychological needs (such as love or affirmation) met through the social networks they inhabit. When needs arise, especially in new or changed surroundings, they impel interpersonal activity meant to satisfy those needs. In this way, people increase their familiarity and comfort with their environments, and they come to expect that their needs will be met in the future through their social networks. On-going difficulties in social and cultural adjustment may be accompanied by anxiety or depression. Psychology of Adjustment is an applied Psychology course that teaches the basics of human adjustment in everyday life. Applications of the concepts taught in this course help students understand themselves better, change their behaviors, and enhance their relationships. The term adjustment is often used as a synonym for accommodation and adaptation. Strictly speaking, the term denotes the results of equilibrium, which may be affect by either of these processes (Monroe, 1990). It is used to emphasize the individual's struggle to along or survive in his or her social and physical environment. Good (1959) sates that adjustment is the process of finding and adopting modes of behavior suitable to the environment or the changes in the environment. Shafer (1961) emphasized that adjustment is the process by which a living organism maintains a balance between its needs and the circumstances that in fluency the satisfaction of these needs .Kulshrestha (1979) explained that the adjustment process is a way in which the individual attempts to deal with stress, tensions, conflicts etc., and meet his or her needs. In this process, the individual also makes efforts to maintain harmonious relationships with the environment.

In adjustment, the two crucial factors are the individual and the environment. In the study of the individual, the considerations are the heredity and biological factors, the psychological factors, and the quality of socialization given to him or her. Whereas, the environment includes all the social factors. Every individual from the time he or she steps out of the family and goes to school makes to a long series of adjustments between the whole unique personality and the environment. The ardent desire of each boy and girl to become an individual person having a healthy physique, a growing intellectual ability, a greater degree of emotional poise and increased participation in social groups, such characteristics enhance one's personality. Even parents, teachers and other significant members of the society to which person belong will encourage this desire. The school is the major socialization institution for any child. It is the child's first contract with the world outside the house. For nearly 12 years a child spends 5 to 7 hours a day in the school. School is one the most important foundation pillars on which the child's personality develops. Children learn proficiencies in various abilities like, learning process and homework, social communications, handling emotion, and the management of day to day interactions at home and

*Student, Department of psychology, Banasthali University, Rajasthan

(C) 2014 www.ijip.in 


\section{The International Journal of Indian Psychology: Volume: 01 | Issue: 04 | ISSN 2348-5396}

-school. In reality, the growing child is dependent on the immediate environment i.e. the house and the school to meet his growth needs. The concern, therefore" extends to how the school facilities can be enhanced and improved to meet the growth needs of the children. Several studies have been reported in the area of social, educational, health and emotional adjustment of school students of both sexes. Some studies try to relate adjustment with variables like intelligence, achievement, age, sex, socio-economic status, needs, anxiety, and security. Student's reaction to frustration has also been studied. A few studies focused on the nature, causes, and extent of indiscipline among students. The relation between indiscipline and variables like achievement, participation in co-curricular activities etc., were also examined.

A review of the studies carried out in the field of adjustment as reported in the three surveys of educational research edited by Buch (1991) reveals that no systematic attempt has yet been made to develop a tool for the assessment of adjustment problems of students.

\section{Emotion control:}

Many contemporary theories of emotion contend that emotion is organized around two primary motivational systems (Davidson \& Irwin, 1999; Gray, 1994; Lang, Bradley, \& Cuthbert, 1990; Schneirla, 1959). The defensive system is responsible for withdrawal or avoidance behavior and mediates unpleasant emotions. The appetitive system is responsible for approach behavior and underlies pleasant emotions. There is flexibility, however, in the expression of emotion because fear does not always result in our running away or anger in our striking out. In other words, we are able to control our emotions. Emotion control, the term most often used in the literature, has been defined as the processes by which "individuals influence which emotions they have, when they have them, and how they experience and express these emotions" (Gross, 1999, p. 557). Emotion control may occur volitionally when an individual has an explicit goal to modify his/her current motional state or automatically when there is no explicit regulatory goal but the emotional response is modified nonetheless (Gross \& Thompson, 2007).

In other words, we may deliberately control the way we think about an emotional stimulus or how we direct our attention in order to change how we feel, or we may unintentionally change how we feel through our direct experiences such as becoming desensitized to violent media images or habituating to noxious stimuli. Controlled regulation involves the selection of a strategy to alter or maintain an emotional state in line with current goals (Bergh \& Williams, 2007). Gross (1998) classified regulation strategies into antecedent-focused strategies, which are aimed at the emotion-eliciting stimulus, and response-focused strategies, which are aimed at the behavioural or physiological responses elicited by a stimulus or situation.

Cognitive reappraisal refers to taking a different perspective on an emotional stimulus by re-interpreting the initial appraisal (Lazarus, 1991). Attention deployment refers to controlling the focus of attention toward or away from an emotional stimulus (Ochsner \& Gross, 2007). It is possible that these two strategies may recruit different cognitive processes (Ochsner\& Gross, 2005), which may be more or less affected by the aging process. These strategies were employed in thisthesis to examine whether age differences in emotion regulation, if found, could be attributed toa particular strategy rather than to a more generalized inability to regulate emotion. Many different definitions of emotion regulation and ways of operational zing the concept have been proposed. Shields and Cicchetti (1997) characterized emotion regulation as efforts to regulate emotion with the goal of modifying arousal to achieve optimal engagement with the environment. Further, they proposed that temporal features of emotion such as liability, flexibility, and situational responsively of expressed emotions all reflect emotion regulation processes. These features have also been referred to as emotionality (Rothbart, Ahadi \& Evans, 2000). Other definitions of emotion regulation concentrate more on the mechanisms and processes involved in regulating one's emotions. Gross (1998) defines emotion regulation as processes that influence which emotions individuals

(C) 2014 www.ijip.in
July-September 2014
$130 \mid \mathrm{P}$ a g e 


\section{The International Journal of Indian Psychology: Volume: 01 | Issue: 04 | ISSN 2348-5396}

experience, as well as when and how they express their emotions. Gross notes that both positive and negative emotions can be regulated, and regulation can occur without conscious awareness. Thompson (1994) suggested that emotion regulation processes include both extrinsic and intrinsic processes that aid in monitoring, evaluating, and modifying emotional responses in order to achieve one's goals.

This includes regulating emotional arousal through enhancement and maintenance as well as inhibition of emotional arousal, and regulation efforts can impact the intensity and duration of experienced emotions. While many conceptualizations of emotion regulation have been utilized, all of the definitions of emotion regulation emphasize that the ability to successfully coordinate one's emotions with the varying stresses of the environment is essential to adaptive functioning (Durbin \& Shafir, 2007). It may be that children who experience more intense and frequent emotions have more difficulty in modifying these emotions and thus are more prone to experiencing symptoms of depression. Consistent with this hypothesis, the experience of internalizing symptoms has been linked to temporal features of children's emotion regulation including the frequency, duration, intensity, and recovery of expressed emotions. Specifically, children in fourth and fifth grade with internalizing symptoms have been found to have a higher level of fear emotionality (Rydell, Berlin, \&Bohlin, 2003). Another study found that children five to eight years old with internalizing symptoms have been found to be more likely to express their anger and sadness in ways that are excessive and not constructive (Zeman, Shipman, \&Suveg, 2002). In addition, depressive symptoms in early to mid-adolescence have been linked to experiencing greater labiality and intensity of sadness, anger, and anxiety (Silk, Steinberg, \& Morris, 2003). Internalizing symptoms may also be related to emotion regulation processes. Emotion regulation processes refers to how emotions are managed after they are aroused and experienced at a certain level of intensity (Rydell, Berlin \& Bohlin, 2003). As noted earlier (Thompson, 1994), emotion regulation processes are involved in the evaluation, monitoring, and modification of emotion. Specifically, more depressed children may process emotional events in a biased way. For example, depressed children ages eight to sixteen have difficulties inhibiting the processing of negative emotional information in order to concentrate on another task (Ladouceur, Dahl, Williamson, Birmaher, Ryan \& Casey, 2005). Based on Beck's model of depression, Leitenberg (1984) proposed four common errors in the thinking of depressed children.

Overgeneralization occurs when an individual assumes that an outcome in one situation will always occur in responses to that situation and similar situations in the future. Catastrophzing occurs when an individual misconstrues an event as catastrophic or expects the outcome of an event will be disastrous. Personalization transpires when an individual interprets negative events as having some sort of personal significance or feels personally responsible for these events. Selective abstraction refers to instances in which the individual concentrates on only negative aspects of a situation. Increased cognitive errors have been linked to both depressive symptomatology and clinical depression in middle childhood (Leitenberg, 1994; Epkins, 1998; Cole \& Turner, 1993; Tems, Stewart, Skinner, Hughes, \& Emslie, 1993). Further, cognitive errors explain unique variability in depressive symptomatology above and beyond both the perceived and actual competence of the child (Epkins, 1998). Another aspect of emotion regulation that may be related to depressive symptoms is the monitoring of one's emotions. Monitoring one's emotional state includes having an awareness of one's emotions (Thompson, 1994). Individuals who have an impoverished awareness of their emotions may consequently experience difficulties in the regulation and expression of these emotions, which may affect their susceptibility to developing depression (Lane \& Schwartz, 1987). For example, children who are aware of their emotions may be more able to consider and execute strategies which allow the individual to better cope with the situation which initially evoked the emotion (SouthamGerow\& Kendall, 2000). Poor awareness of emotions has been found to be positively correlated with internalizing symptoms (Zeman, Shipman \&Suveg, 2002), and specifically, depressive symptomatology (Penza-Clyve \& Zeman, 2002). Thus, it seems likely that if children lack awareness of their emotions, they may not engage in constructive coping strategies that would allow the modification of the problematic situations and emotions.

(C) 2014 www.ijip.in

July-September 2014

131 | P a g e 


\section{The International Journal of Indian Psychology: Volume: 01 | Issue: 04 | ISSN 2348-5396}

Emotion regulation also refers to processes that can modify emotion, such as coping strategies (Thompson, 1994). Children who are not able to effectively alter or address their negative emotions through coping strategies are likely more at risk for experiencing depressive symptoms. Coping refers to the efforts made by children to regulate responses which may arise due to stressful events, including their emotions, cognitions, and behavioural and physiological responses (Compas, Connor-Smith, Saltzman, Thomsen, \& Wadsworth, 2001). Coping can be both cognitive and behavioral in nature. For example, Ayers, Sandler, West \& Roosa (1996) discussed avoidant coping as including both actions (e.g., coping by avoiding problems) and cognitions of avoidance (e.g., refusing to think about it).

\section{Self-control of emotion:}

Like other areas of self-control, understanding the development of control of emotions necessitates examination of both intrinsic and extrinsic factors (Calkins, 1994). Intrinsic factors mean those individual differences that are usually thought of as "innate." However, according to Gottlieb, 1991, no differences in physical, physiological, or biological characteristics are ever solely the result of genes without important environmental input. Intrinsic factors include the temperamental disposition of the child, certain cognitive skills, and the underlying neural and physiological systems that support and are engaged in the process of control (Calkins, 1994; Fox, 1994; Fox, Henderson, \& Marshall, 2001). Extrinsic factors include the manner in which caregiver's shape and socializeemotional responses of the child. In addition, other socializing agents, including siblings and peers, influence the extent to which children successfully utilize self-control strategies. Over the past 10 years there has been an increased recognition of the importance of self-control of emotion in the developmental literature (e.g., Fox, 1994). It has also led to some confusion or ambiguity as to exactly what is meant by "regulation" of emotion. Some have argued that emotion regulation is defined by both the intrinsic and extrinsic processes involved in the monitoring, evaluating, and moderating of emotional responses (Thompson, 1994). Others have noted that emotions themselves regulate social interaction (Campos, Mumme, Kermoian, \&Campos, 1994). Redefining emotion regulation as the processes involved in self-control of emotion may help eliminate some of the ambiguity in these definitional issues. Defining self-control of emotion first necessitates agreement on the nature of emotion. Most contemporary definitions of emotion agree that it is a psychological state of specific duration that involves expressive behaviour for communication. This state is the result of cognitive appraisal or evaluation of a change in the environment. It may also involve peripheral physiological changes that contribute to the intensive aspects of the state.

\section{Perceived loneliness:}

Even though the phenomenon of loneliness has been described in literature and arts since ancient time, it is difficult to define it. Loneliness is universal, still very subjective feeling, natural to all human beings. For its subjectivity, many people may be ashamed of talking about it or admitting they feel lonely because they are afraid of being stigmatized. Loneliness may also have different meaning for different people which makes understanding of loneliness even more difficult. (Killeen 1998, 763-764.

Philosophy and literature have provided different points of view on loneliness over past centuries. Ancient Greek philosophers saw people as social beings and therefore, loneliness was something undesirable. In Christianity, on the other hand, loneliness has represented a way of one's self-fulfillment and connection with God. By contrast, romanticism deals with loneliness as one's fate, unwanted but unchangeable. Romantic heroes rebel against conventions and laws given by hypocritical society and they become outcasts. In spite of being strong individuals, they feel lonely and end tragically. Finally, existentialists and humanists give another perspective of loneliness. Although they agree that person stands and acts alone and he alone is responsible for his own choices, humanists add that loneliness is a choice of one's own free will. (Karnick 2005, 8-9.)

(C) 2014 www.ijip.in 


\section{The International Journal of Indian Psychology: Volume: 01 | Issue: 04 | ISSN 2348-5396}

Killeen (1998) summarizes all these perspectives into alienation-connectedness continuum. Beginning from the negative side, there are estrangement and alienation, a rejection by others or a feeling of a complete worthlessness. Next to them stays loneliness which is viewed as "emptiness due to an unfulfilled social and or emotional life" (Killeen 1998, 764). Social isolation and aloneness are two other related concepts. Social isolation balances between loneliness and aloneness, depending on whether it is one's choice or not. Consequently, aloneness can be understood as one's preference of being alone. Unlike previous concepts, solitude has a positive meaning. It is a time on one's own that can be used for self-reflection and creativity. Killeen also covers a concept of connectedness in her work. (Killeen 1998, 764-765.) This concept was first mentioned by Younger (1995) who proposes that through suffering of loneliness, one can find connection with others, nature and universe. Further, some authors, based oninteractionism theory, distinguish between emotional and social aspects of loneliness (Younger 1995; Donaldson \& Watson 1996, 955; Killeen 1998, 764).

Whereas the social element simply means lack of social contacts or disaffection with a present social network (Savikko 2008, 14), Younger (1995) depicted the emotional loneliness as: "the kind of desperate, lonely Why? Felt by most anyone in moments of crushing hurt, ruin, and deepest despair. ... That which gave life its meaning has become empty and void." Besides, integrationists believe that one's personality determines how loneliness is perceived. According to this theory, not only quality but also the extension of loneliness may be evaluated. Interactions theory was criticized for excluding positive side of loneliness; absence of others does not necessarily have to be a negative experience. (Donaldson \& Watson 1996, 955; Savikko 2008, 16.)

Thus, according to definition given by Rook (1984, according to Donaldson \&Watson 1996, 953), loneliness is: "an enduring condition of emotional state that arises when a person feels estranged from, is misunderstood or rejected by others, and or lacks appropriate social partners for desired activity, particularly activities that provide a sense of social integration and opportunities for emotional intimacy". (Rook 1984, according to Donaldson \& Watson 1996, 953)

\section{REVIEW OF LITERATURE}

\section{Adjustment problem among adolescents:}

The problem of adjustment is so important that psychologists and social scientists are now agreed on issue that most of interpersonal, inter-group and person- group relations in various intensities are the product of success or failure of adjustment. Kulshrestha (1979) describes adjustment is a way in which the individual attempts to deal with stress, tension, conflict, anxiety etc. and meets his/her needs. Adjustment is, thus a state of harmony between the individual and his/her social environment. One's adjustment is influenced by several factors in society as well as the factors within the person and (Psychological) concerned. Several studies have been conducted in the areas of social, educational, health and emotional adjustment of school students of both sexes. Mohsin, et.al. (1985) have reported that male subjects have higher adjustment than female subjects. Singh (1995) observed that early adolescent girls were better adjusted in the areas of home and emotional, whereas early adolescent boys were better adjusted in the areas of health and social adjustment. Raju and Rahamtullah (2007) stated that boys are significantly better adjusted than girls on the emotional adjustment area. Abdullah (2009) found significant sex difference in the level of adjustment problem.

Mahmondi (2010) found that gender had no differential influence over adjustment scores in home, health, emotional and social area. Roy, Ekka and Ara (2011) observed that female students were better adjusted than male students. 


\section{The International Journal of Indian Psychology: Volume: 01 | Issue: 04 | ISSN 2348-5396}

\section{Emotional control/regulation among adolescents:}

Recent research has led to an increased interest in the role of emotional processes in normal and atypical development (Southam-Gerow\& Kendall, 2001), with the regulation and deregulation of emotions being a primary focus of this research. Indeed, emotion regulation (ER) difficulties have been implicated in several forms of developmental psychopathology (e.g., Bradley,2000; Cole, Michel, \&Teti, 1994; Gross, 1998). Furthermore, ER skills have been positively linked to both pro social behaviour (e.g., Shields, Cicchetti, \& Ryan, 1994) and resiliency to multiple risks (Lengua, 2002) among children. In contrast to the growing body of literature on ER among children and adults, few studies have investigated ER and ER difficulties in adolescents (Gross, 1998; Zeman, Cassano, Perry-Parrish, \& Stegall, 2006). However, emerging evidence for the central role of ER processes in adolescent development (e.g., Garnefski, Kraaij, \& van Etten, 2005; Silk, Steinberg, \& Morris, 2003) highlights the importance of examining ER among adolescents. One likely reason for the relative lack of research in this area (despite its clear clinical significance) may be the limited number of available measures of ER for adolescents (Zeman et al., 2006). Thus, the primary goal of the present study was to extend the extant research on adolescent ER difficulties by exploring the factor structure and psychometric properties of an existing adult measure of ER difficulties among adolescents. One promising measure for the comprehensive assessment of ER difficulties is the Difficulties in Emotion Regulation Scale (DERS; Gratz \& Roemer, 2004). Originally developed for use with adults, the DERS was designed to provide a comprehensive assessment of clinically relevant ER difficulties across multiple domains. Moreover, suggesting its potential utility for adolescents, the DERS is based on a conceptual definition of ER influenced most directly by theoretical literature on ER in youth (Cole et al., 1994; Thompson, 1994). Items of the DERS focus mainly on the regulation of negative emotional states, as difficulties in this domain are considered to have particular clinical relevance.

Whereas much of the literature on ER in adulthood emphasizes the control and reduction of negative emotions, the childhood literature emphasizes the functionality of emotions and the problems associated with deficits in the capacity to experience the full range of emotions, with some developmental researchers defining ER as "...the extrinsic and intrinsic processes responsible for monitoring, evaluating, and modifying emotional reactions to accomplish one's goals" (Thompson, 1994, pp.27-28). Further, research using this measure with adults has repeatedly linked the DERS to clinically-relevant phenomena in both clinical and nonclinical samples. Specifically, scores on the DERS showed statistically significant relations with behaviours thought to serve an emotion regulating function, including deliberate self-harm (Gratz \& Roemer, 2008), intimate partner abuse perpetration among men (Gratz, Paulson, Jakupcak, \&Tull, 2009), and cocaine-dependence (Fox et al., 2007). Further, scores on the DERS have been found to be heightened among individuals with psychiatric disorders thought to be characterized by ER difficulties, including borderline personality disorder (BPD; vs. non-PD outpatients; Gratz, Rosenthal, Tull, Lejuez, \& Gunderson, 2006),probable PTSD (vs. trauma-exposed individuals without PTSD; Tull, Barrett, McMillan, \&Roemer, 2007), and panic attacks (vs. non-panickers; Tull\& Roemer, 2007).

\section{Perceived loneliness:}

Loneliness is a very important factor affecting our overall mental health and achievement in life. Loneliness has been studied in various areas like:

\section{Loneliness in Adolescents:}

Thought there are many theoretical approaches to identify predictors of loneliness, researchers interested in loneliness have generally agreed on two characteristics of the loneliness experience. Loneliness is an aversive experience, similar to other negative affective states such as depression or anxiety. Loneliness is distinct from social isolation and reflects an individual's subjective perception of deficiencies in one's network of social relationships (Peplau \& Perlman, 1982). 


\section{The International Journal of Indian Psychology: Volume: 01 | Issue: 04 | ISSN 2348-5396}

\section{Attributes of loneliness:}

Contemporary researchers such as Kupersmidt (1999) suggest that loneliness is related to a range of emotional, social and behavioral problems for children, adolescents and adults. Emotional problems are apparent in low selfesteem (Hymel, Rubin, Towden, \& Lemare, 1990) depression (Goswick \& Jones, 1981), and social anxiety (Moore $\&$ Shultz, 1983). Behavioral problems found to impact loneliness in adolescence might include shyness, social withdrawal, spending more time alone (Horowitz, French, \&Anderson, 1982; Goswick \& Jones, 1981; Russell, Peplau, \& Cutrona, 1980), dating frequency and decreased participation in religious and extracurricular activities (Brennan, 1982). Similarly, social problems that impact loneliness include peer rejection and victimization, lack of friendships, and lack of high quality friendships (Asher et al., 1984; Asher \& Wheeler, 1985; Boivin \& Hymel, 1997; Crick \& Ladd, 1993; Kochenderfer \&Ladd, 1996). In addition, Boivin reported that rejected children who are submissive in their behaviour have also been found in several studies to report more loneliness and social dissatisfaction than average-status children (Boivin, Pulin, \&Vitaro, 1994; Parker \&Asher, 1993).

\section{Effects of the school/ environment:}

In most parts of the world, schools and classrooms play an integral role in establishing peer relationships and creating strong bonds of lasting friendships. However, this is not always the case for many young adolescents. Consequences of changing school environments from middle to secondary school can often manifest difficulties in making initial adjustments. Students often report a sense of uneasiness and disconnection, feeling that the high schools are less person-oriented and thus deny them the opportunity to build attachments and find support with teachers as they had in the primary grades (Cotterell, 1996).

Larson (1980) reported that, in the context of the importance of social connection for adolescents, school settings and peer relationships may often generate more feel in gsofloneliness. Teens do not just feel alienated from peers; they feel like they have failed a critical task of being socially connected. Larson's (1980) found that when loneliness occurred it was often associated with mal adjustment. Larson indicated that adolescents, who reported feeling more lonely with others in school and in public settings during this time, are more likely to show depression, lower self-esteem, lower GP A, and have more problem behaviours as rated by parents and teachers.

\section{Peer influences:}

Much of the literature pertaining to the incidence of loneliness amongst adolescents has centered on the importance of understanding the developmental stages young people encounter. Inderbitzen- Pisaruk, Clark and Solano (1992) believed that adolescents are particularly vulnerable to loneliness due to the increased importance of friendship during the developmental stage.

Loneliness is powerfully experienced in adolescence as a result of an increased need for intimacy and self-disclosure, which may only be satisfied by close relationships with same and opposite-sex peers (Brennan, 1982). According to Bell (1981) the importance of friends and peer group involvement increases with age and peaks during the tenth grade.

In a concurrent study carried out by Marcoen and Goossen (1987) reporting on peer loneliness, the authors indicated that a developmental trend toward decreased peer related loneliness occurred at an earlier age for girls than it did for boys which may suggest that girls are less lonely as they age. Some researchers have suggested that girls are less lonely than their counterparts because they remain far more social through the school years. Rafaelli (1989) found that the increased social time of girls relative to boys could be explained by the increased amount of time girls spend talking with friends. The social aspect of their development can be interpreted as a support that is interpersonally focused and may help to defer loneliness.

(C) 2014 www.ijip.in

July-September 2014

135 | P a g e 


\section{The International Journal of Indian Psychology: Volume: 01 | Issue: 04 | ISSN 2348-5396}

During early adolescence social rejection, domination, and teasing promote loneliness by encouraging sensitive individuals to see themselves as unacceptable and lacking social worth and standing, resulting in an enduring sense of social isolation.(Guttmann\& Parker, 1986; Parkhurst \& Asher, 1992; Rubin \& Mills, 1991). Moore and Schultz (1983) stressed that those adolescents who were lonely usually remained lonely and seldom initiated interactions with others. Efforts to investigate the quality of friendship and loneliness are pronounced in friendships that lack supportive or affirming resources. Parker and Asher (1993) findings supported the premise that friendships differ in quality and that those 1acking in key support, or having high levels of conflict, are less likely to remain intact and more likely to foster feelings of loneliness. Consistent with these premises, Ladd, Kochenderfer and Coleman (1996) illustrated that classmates demonstrated direct positive behaviour toward "liked" children, but treated "disliked" peers more punitively. These authors speculated that this experience thwarts basic needs that children have to belong and may give rise to affective states such as feelings of alienation and loneliness.

\section{Families:}

Families play an integral role in adolescent loneliness. Findings yielded by Rotenberg's study (1995) designed to examine how parenting styles affect their children, suggested that adolescents who reported that their parents were warm and involved in their lives were less likely to report being lonely. Interestingly, mothers' loneliness was positively associated with their adolescents' loneliness. These findings are consistent with the hypothesis that mothers hand down their loneliness to their adolescent by tending not to promote positive peer relationships. In contrast, Belsky (1981) suggested that parents may be less inclined to assume responsibility for their adolescents than they did when they were children, and speculated that adolescents affect their parents' behaviour, and that they engage in reciprocal patterns of interaction. Goossen and Marcoen (1987) concluded that, from grade five until the end of high school, adolescents experience increased loneliness in relations with parents, accompanied by a clear decline in peer-related loneliness from early adolescence onwards. The latter may be explained in terms of developmental and identity exploration, as adolescents begin the process of detaching from parents and searching for more meaningful peer relationships.

\section{Gender implications:}

According to Koenig and Abrams' (1999), there is a gender difference in loneliness; it emerges during the period of adolescence. In their meta-analysis focusing on childhood and adolescent gender differences related to loneliness, with use of the VCLA Loneliness Scale, results indicated that, despite some inconsistent findings, the overall pattern suggested that a gender difference in loneliness emerged during adolescence with boys reporting more loneliness than girls. Results of Ladd et al. 1996 study carried out on the gender-dependent correlates of loneliness supported the above statement suggesting that at higher levels of friendship, conflict was associated with increased loneliness in boys.

However, some researchers have argued that, in order to ascertain if gender differences exist, research needs to encompass variables that measure different behavioral tendencies of the lonely adolescent. Crick and Ladd (1993), in earlier studies carried out targeting depressed adolescents, found that gender differences are significant and results will differ when researchers take into account aspects of behavior associated with adolescent loneliness. Interestingly, they explained that, when behaviour was accounted for, girls who received poor treatment from peers resulting in low peer acceptance demonstrated increased levels of loneliness. 


\section{The International Journal of Indian Psychology: Volume: 01 | Issue: 04 | ISSN 2348-5396}

\section{METHODOLOGY}

\section{Rationale of the study:}

Adolescence is a stage of life when an individual faces many conflicts and has to undergo many changes in the physical, emotional and social domain. Self-regulation is a big problem for adolescents and a large part of it includes regulation of emotions. Need to form bonds with others including the need-to love and be loved; to appreciate and be appreciated is dominant in this stage. Criticism and rejection are unbearable and when this need is not satisfied, the adolescent starts to feel lonely. The school environment is also a very important factor in enabling the student in becoming better adjusted and self-regulated. Those who study in a residential environment far away from their homes have certain different experiences and face different challenges as compared to the students living with their parents-in their own hometown. The present study thus focuses on the effect of type of schooling (living in a hostel and living at home) on the adjustment, emotional control and perceived loneliness among adolescents. The study would also try to explore the gender differences in affecting the aforementioned dependent variables.

Problem: To study the effect of type of schooling and gender on adjustment, emotional control and perceived loneliness among adolescents.

\section{Objectives:}

1. To study the effect of type of schooling on the adjustment of adolescents.

2. To study the effect of type of schooling on the emotional control of adolescents.

3. To study the effect of type of schooling on the perceived loneliness of adolescents.

4. To study the effect of gender on the adjustment of adolescents.

5. To study the effect of gender on the emotional control of adolescents.

6. To study the effect of gender on the perceived loneliness of adolescents.

7. To study the interaction effect of type of schooling and gender on adjustment of adolescents.

8. To study the interaction effect of type of schooling and gender on emotional control of adolescents.

9. To study the interaction effect of type of schooling and gender on perceived loneliness of adolescents.

\section{Hypotheses:}

1. There will be significant difference between adjustment of hostellers and day-scholars.

2. There will be significant difference between emotional control of hostellers and day-scholars.

3. There will be significant difference between perceived loneliness of hostellers and day-scholars

4. There will be significant difference between adjustment of male and female adolescents.

5. There will be significant difference between emotional control of male and female adolescents.

6. There will be significant difference between perceived loneliness of male and female adolescents.

7. The interaction effect of type of schooling and gender on adjustment would be significant.

8. The interaction effect of type of schooling and gender on emotional control would be significant.

9. The interaction effect of type of schooling and gender on perceived loneliness would be significant.

\section{Subjects:}

Total 120 adolescents (60 boys and 60 girls) of age group 14-17 years were randomly selected out of which residential boys were taken from the students residing in Chaudhry Charan Singh boys hostel, Shikarpur, Uttar Pradesh and girls were taken from Kaka Girls P.G College, Sikandrabad and day-scholar girls and boys both were be taken from the students studying in Saraswati Vidya Mandir, Sikandrabad, Uttar Pradesh.

(C) 2014 www.ijip.in

July-September 2014

137 |P a g e 


\section{The International Journal of Indian Psychology: Volume: 01 | Issue: 04 | ISSN 2348-5396}

Research Design: 2 (type of schooling: day scholar and hosteller) $\times 2$ (Gender: female and male) Factorial design was utilized in studying the effect of gender and type of schooling (hostellers and day-scholars) on adjustment, emotional control and perceived loneliness.

\section{Variables:}

\section{Independent variables:}

Type of schooling (hostellers and day-scholars)

Gender

\section{Dependent variables:}

Adjustment

Emotional control

Perceived loneliness

\section{Tools:}

Adjustment inventory for college students (AICS): For assessing the adjustment, a self-report questionnaire, Adjustment Inventory for College Students (AICS), designed by Prof. R.P. Sinha (Patna) was used. This inventory has 5 areas of adjustment (Home, Health, Social, Emotional, and Educational). The inventory has been prepared in Hindi as well as English and it has 102 items (Home16, Health15, Social19, Emotional 31, and Educational 21). The split- half and test- retest reliability of the inventory are found to be .94 and .93 respectively. The validity of this inventory is also well established.

Emotional Control Scale(ECQ): The ECQ was developed by Roger \&Najarian, 1989 .It measures people's ability to control emotion in trying circumstances, and consists of scales for measuring "Aggression Control", "Rehearsal", "Benign Control", and "Emotional Inhibition", Participants rate statements true or false of themselves on each of the 14-item scales. Example items and alphas from each scale are as follows: Rehearsal $(=0.80$; "I find it hard to get thoughts about things that upset me out of my mind.'); Emotional inhibition $(=0.77$; "When something upsets me, I prefer to talk to someone about it rather than bottle it up" $)$, Benign control (=0.63; "I often say things without thinking whether I might upset others"), and Aggression control (=0.72; "'If someone pushed me, I would push back.' ').

UCLA Loneliness scale (Russell, D, Peplau, L. A \& Ferguson, M. L. (1978): It is a 20-item scale designed to measure one's subjective feelings of loneliness as well as feelings of social isolation. Participants rate each item as either O ("I often feel this way"), S ("I sometimes feel this way"), R ("I rarely feel this way"), N ("I never feel this way").

\section{Statistical Analysis:}

F test (two way ANOVA) and descriptive statistics were utilized in studying the effect of gender and type of schooling ( hostellers and day-scholar) on the dependent variables.

\section{Procedure:}

Total 120 adolescents (60 boys and 60 girls) of age group 14-17 years were randomly selected out of which residential boys were taken from the students residing in Chaudhry Charan Singh boys hostel, Shikarpur, Uttar Pradesh and girls were taken from Kaka Girls P.G College, Sikandrabad and day-scholar girls and boys both were taken from the students studying in Saraswati VidyaMandir, Sikandrabad. Prior consent was taken from participants and all questionnaires were administered to them. Scoring was done with the help of the respective manuals of the tests. Data were entered, calculated and interpreted with the help of SPSS software (version 16). 
The International Journal of Indian Psychology: Volume: 01 | Issue: 04 | ISSN 2348-5396

\section{RESULT}

Table 1: Showing Mean and SD of day scholars and hostellers in terms of Dependent Variables.

\begin{tabular}{|l|c|c|c|c|}
\hline \multicolumn{1}{|c|}{ Dependent variables } & \multicolumn{2}{|c|}{ Mean } & \multicolumn{2}{c|}{ Standard Deviation } \\
\hline & $\begin{array}{c}\mathbf{M}_{\mathbf{1}} \text { (day } \\
\text { scholars) }\end{array}$ & $\mathbf{M}_{\mathbf{2}}$ (hostellers) & $\begin{array}{c}\text { SD }_{\mathbf{1}} \text { (day } \\
\text { scholars) }\end{array}$ & $\mathbf{S D}_{\mathbf{2}}$ (hostellers) \\
\hline Total Adjustment & 50.30 & 48.23 & 13.33 & 15.35 \\
\hline Home Adjustment & 7.23 & 6.65 & 2.82 & 2.90 \\
\hline Socialth Adjustment & 6.28 & 7.36 & 2.17 & 3.27 \\
\hline Emotional Adjustment & 15.21 & 7.51 & 2.19 & 2.54 \\
\hline $\begin{array}{l}\text { Educational } \\
\text { Adjustment }\end{array}$ & 9.55 & 16.11 & 4.36 & 5.33 \\
\hline Emotional Control & 30.03 & 8.90 & 3.52 & 3.97 \\
\hline Perceived Loneliness & 48.41 & 30.23 & 3.78 & 4.67 \\
\hline
\end{tabular}

Table 1: Shows the mean \& SD of day scholars and hostellers in terms of total adjustment. The mean and S.D. for total adjustment are $50.30(13.33) \& 48.23(15.35)$, for home adjustment are $7.23(2.82) \& 6.65(2.98)$, for health adjustment are $6.28(2.17) \& 7.36$ (3.27), for social adjustment are: 9.15 (2.19) \&7.51 (2.54), for emotional adjustment are:15.21(4.36) \& 16.11(5.33), for education adjustment are:9.55(3.52) \& 8.90(3.97) for emotional control are: 30.03(3.78) \& 30.23(4.67), for perceived loneliness are:48.41(6.25) \& 50.75(6.46).

Table 2: Showing Mean and SD of males and females in terms of dependent variables

\begin{tabular}{|l|c|c|c|c|}
\hline \multicolumn{1}{|c|}{ Group } & \multicolumn{2}{c|}{ Mean } & \multicolumn{2}{c|}{ Standard Deviation } \\
\hline Total Adjustment & $\mathbf{M}_{\mathbf{1}}$ (male) & $\mathbf{M}_{\mathbf{2}}$ (female) & $\mathbf{S D}_{\mathbf{1}}$ & $\mathbf{S D}_{\mathbf{2}}$ \\
\hline Home Adjustment & 50.51 & 48.01 & 14.48 & 14.22 \\
\hline Health Adjustment & & & & \\
\hline Social Adjustment & 7.53 & 7.35 & 2.80 & 2.89 \\
\hline Emotional Adjustment & 7.90 & 6.61 & 2.46 & 3.14 \\
\hline Educational Adjustment & 15.56 & 8.76 & 2.58 & 2.36 \\
\hline Emotional Control & 9.41 & 15.76 & 5.01 & 4.76 \\
\hline Perceived Loneliness & 30.48 & 9.03 & 3.72 & 3.80 \\
\hline
\end{tabular}

Table 2: Shows the mean \& SD of female and male in terms of total adjustment 50.51 (14.48) \& 48.01(14.22), home adjustment 6.53(2.80) \&7.35(2.89), health adjustment 7.03 (2.46) \& 6.61 (3.14), social adjustment 7.90 (2.58) \&8.76 (2.36), emotional adjustment 15.56 (5.01) \&15.76 (4.76), education adjustment 9.41 (3.72) \& 9.03 (3.80), emotional control 30.48 (4.77) \& 29.78 (3.62), perceived loneliness 49.66 (6.43) \& 49.48(6.49). 
The International Journal of Indian Psychology: Volume: 01 | Issue: 04 | ISSN 2348-5396

Table 3: 2x2 ANOVA showing effect of Type of schooling and Gender on Total Adjustment

\begin{tabular}{|l|c|c|c|c|c|}
\hline \multicolumn{1}{|c|}{ Source } & S.S & df & Mean Square & F & Sig. \\
\hline Type of schooling & 128.13 & 1 & 128.13 & $.61^{\text {NS }}$ & .43 \\
\hline Gender & 187.50 & 1 & 187.50 & $.90^{\text {NS }}$ & .34 \\
\hline $\begin{array}{l}\text { Type of schooling } \times \\
\text { Gender }\end{array}$ & 116.03 & 1 & 116.03 & $.55^{\text {NS }}$ & .45 \\
\hline Error & 24085.80 & 116 & 207.63 & & \\
\hline
\end{tabular}

\section{NS = Not significant}

Table 3: shows the individual effect of type of schooling and gender on total adjustment separately. The $F$ value for type of schooling was found to be .61 which is statistically not significant .The $\mathrm{F}$ value for gender was found to be .90 which is statistically not significant. The interaction effect of type of schooling and gender on total adjustment was also found to be not significant as $\mathrm{f}=.55$.

Table 4: 2x2 ANOVA showing effect of Type of schooling and Gender on Home adjustment.

\begin{tabular}{|l|c|c|c|c|c|}
\hline \multicolumn{1}{|c|}{ Source } & S.S & df & Mean Square & F & Sig. \\
\hline Type of schooling & 10.20 & 1 & 10.20 & $1.29^{\mathrm{NS}}$ & .25 \\
\hline Gender & 20.00 & 1 & 20.00 & $2.54^{\mathrm{NS}}$ & .11 \\
\hline $\begin{array}{l}\text { Type of schooling * } \\
\text { Gender }\end{array}$ & 35.20 & 1 & 35.20 & $4.47^{*}$ & .03 \\
\hline Error & 913.16 & 116 & 7.87 & & \\
\hline
\end{tabular}

\section{$*=\mathrm{p}<.05, \mathrm{NS}=$ not significant}

Table 4: shows the individual effect of type of schooling and gender on home adjustment separately. The F value for type of schooling was found to be 1.29 which is statistically not significant. The $F$ value for gender was found to be 2.54 which is statistically not significant. The interaction effect of type of schooling and gender on home adjustment was found to be significant as $\mathrm{f}=4.47$.

Table 5: 2x2 ANOVA showing effect of Type of schooling and Gender on Health adjustment.

\begin{tabular}{|l|c|c|c|c|c|}
\hline \multicolumn{1}{|c|}{ Source } & S.S & df & $\begin{array}{c}\text { Mean } \\
\text { Square }\end{array}$ & F & Sig. \\
\hline Type of schooling & 35.20 & 1 & 35.20 & $4.51^{*}$ & .03 \\
\hline Gender & 5.20 & 1 & 5.20 & $.66^{\mathrm{NS}}$ & .41 \\
\hline $\begin{array}{l}\text { Type of schooling } \times \\
\text { Gender }\end{array}$ & 1.40 & 1 & 1.40 & $.18^{\mathrm{NS}}$ & .67 \\
\hline Error & 905.50 & 116 & 7.80 & & \\
\hline
\end{tabular}

\section{$*=\mathrm{p}<.05, \mathrm{NS}=$ not significant}

Table 5: shows the individual effect of type of schooling and gender on health adjustment separately. The F value for type of schooling was found to be 4.51 which is statistically significant .The $F$ value for gender was found to 
The International Journal of Indian Psychology: Volume: 01 | Issue: 04 | ISSN 2348-5396

be .66 which is statistically not significant. The interaction effect of type of schooling and gender on health adjustment was also found to be not significant as $\mathrm{f}=.18$.

Table 6: $2 \times 2$ ANOVA showing effect of Type of schooling and Gender on Social adjustment.

\begin{tabular}{|c|c|c|c|c|c|}
\hline Source & S.S & df & $\begin{array}{c}\text { Mean } \\
\text { Square }\end{array}$ & F & Sig. \\
\hline Type of schooling & 80.03 & 1 & 80.03 & $15.32^{* *}$ & .00 \\
\hline Gender & 22.53 & 1 & 22.53 & $4.31^{*}$ & .04 \\
\hline $\begin{array}{c}\text { Type of schoolingx } \\
\text { Gender }\end{array}$ & 36.30 & 1 & 36.30 & $6.95^{*}$ & .01 \\
\hline Error & 605.80 & 116 & 5.22 & & \\
\hline
\end{tabular}

$*=\mathrm{p}<.05, * *=\mathrm{p}<.01$

Table 6: shows the individual effect of type of schooling and gender on social adjustment separately. The F value for type of schooling was found to be 15.32 which is statistically significant .The $\mathrm{F}$ value for gender was found to be 4.31 which is statistically significant. The interaction effect of type of schooling and gender on social adjustment was also found to be significant as $\mathrm{f}=6.95$.

Table 7: 2x2 ANOVA showing effect of Type of schooling and Gender on Emotional adjustment.

\begin{tabular}{|c|c|c|c|c|c|}
\hline Source & S.S & df & $\begin{array}{c}\text { Mean } \\
\text { Square }\end{array}$ & F & Sig. \\
\hline Type of schooling & 24.30 & 1 & 24.30 & $1.01^{\text {NS }}$ & .31 \\
\hline Gender & 1.20 & 1 & 1.20 & $10.05^{\text {NS }}$ & 0.82 \\
\hline $\begin{array}{c}\text { Type of schoolingx } \\
\text { Gender }\end{array}$ & 14.70 & 1 & 14.70 & $.61^{\text {NS }}$ & .43 \\
\hline Error & 2786.46 & 116 & 24.02 & & \\
\hline
\end{tabular}

\section{NS= not significant}

Table 7: shows the individual effect of type of schooling and gender on emotional adjustment separately. The $\mathrm{F}$ value for type of schooling was found to be 1.01 which is statistically not significant .The $\mathrm{F}$ value for gender was found to be .05 which is statistically not significant. The interaction effect of type of schooling and gender on emotional adjustment was also found to be not significant as $\mathrm{f}=.61$.

Table 8

2x2 ANOVA showing effect of Type of schooling and Gender on Educational adjustment.

\begin{tabular}{|c|c|c|c|c|c|}
\hline Source & S.S & df & $\begin{array}{c}\text { Mean } \\
\text { Square }\end{array}$ & F & Sig. \\
\hline Type of schooling & 12.67 & 1 & 12.67 & $.88^{\mathrm{NS}}$ & .34 \\
\hline Gender & 4.40 & 1 & 4.40 & $.30^{\mathrm{NS}}$ & .58 \\
\hline $\begin{array}{c}\text { Type of schooling * } \\
\text { Gender }\end{array}$ & .67 & 1 & .67 & $.04^{\mathrm{NS}}$ & .82 \\
\hline Error & 1663.16 & 116 & 14.33 & & \\
\hline
\end{tabular}

NS= not significant

(C) 2014 www.ijip.in

July-September 2014

$141 \mid \mathrm{P}$ a g e 
The International Journal of Indian Psychology: Volume: 01 | Issue: 04 | ISSN 2348-5396

Table 8: shows the individual effect of type of schooling and gender on education adjustment separately. The F value for type of schooling was found to be .88 which is statistically not significant .The $\mathrm{F}$ value for gender was found to be .30 which is statistically not significant. The interaction effect of type of schooling and gender on educational adjustment was also found to be not significant as $\mathrm{f}=.04$.

Table 9: 2x2 ANOVA showing effect of Type of schooling and Gender on Emotional control.

\begin{tabular}{|c|c|c|c|c|c|}
\hline Source & S.S & df & $\begin{array}{c}\text { Mean } \\
\text { Square }\end{array}$ & F & Sig. \\
\hline Type of schooling & 1.20 & 1 & 1.20 & $.06^{\mathrm{NS}}$ & .79 \\
\hline Gender & 14.70 & 1 & 14.70 & $.80^{\mathrm{NS}}$ & .37 \\
\hline $\begin{array}{c}\text { Type of schoolingx } \\
\text { Gender }\end{array}$ & 7.50 & 1 & 7.50 & $.41^{\mathrm{NS}}$ & .52 \\
\hline Error & 2108.46 & 116 & 18.17 & & \\
\hline
\end{tabular}

\section{NS= not significant}

Table 9:shows the individual effect of type of schooling and gender on emotional control separately. The F value for type of schooling was found to be .06 which is statistically not significant.The $\mathrm{F}$ value for gender was found to be .80 which is statistically not significant. The interaction effect of type of schooling and gender on total emotional control was also found to be not significant as $\mathrm{f}=.41$.

Table 10

2x2 ANOVA showing effect of Type of schooling and Gender on Perceived loneliness .

\begin{tabular}{|l|c|c|c|c|c|}
\hline \multicolumn{1}{|c|}{ Source } & S.S & df & $\begin{array}{c}\text { Mean } \\
\text { Square }\end{array}$ & F & Sig. \\
\hline Type of schooling & 161.00 & 1 & 161.00 & $4.13^{*}$ & .04 \\
\hline Gender & 1.00 & 1 & 1.00 & $.02^{\mathrm{NS}}$ & .87 \\
\hline $\begin{array}{l}\text { Type of schooling * } \\
\text { Gender }\end{array}$ & 261.07 & 1 & 261.07 & $6.71^{*}$ & .01 \\
\hline Error & 4512.23 & 116 & 38.89 & & \\
\hline
\end{tabular}

\section{$*=p<.05, \mathrm{NS}=$ not significant}

Table 10: shows the individual effect of type of schooling and gender on perceived loneliness separately. The F value for type of schooling was found to be 4.13 which is statistically significant.The $F$ value for gender was found to be .02 which is statistically not significant. The interaction effect of type of schooling and gender on perceived loneliness was also found to be significant as $f=6.71$.

\section{DISCUSSION}

The present study aimed to study the effect of type of schooling and gender on adjustment, emotional control and perceived loneliness among adolescents. 


\section{The International Journal of Indian Psychology: Volume: 01 | Issue: 04 | ISSN 2348-5396}

No significant differences were found between day scholars and hostellers in terms of total adjustment which implies that type of schooling didn't have an effect on total adjustment of adolescents. The present findings support previous research (Kakkar, 1967).

According to the knowledge of investigator, very few studies have been reported exploring the effect of type of schooling on home adjustment. The present study however attempted to examine the effect of type of schooling on home adjustment and found that home adjustment of day scholars and hostellers does not differ significantly. The probable reason behind this may be that the sample included in this study comprised of adolescents. Also, if we carefully observe the means of both groups on home adjustment, we find that both groups have not very good home adjustment (which might be attributed to adolescence related conflicts). This means due to the adjustment problems encountered in adolescence, both groups obtained similar means showing no significant differences.

In the present study, type of schooling significantly affected health adjustment as day-scholars have better health adjustment in comparison to the hostellers. This finding supports previous research (Perveen \& Kazmi, 2011).

In the present study, type of schooling significantly affected social adjustment of adolescents. Hostellers were found to be better socially adjusted in comparison to the day scholars. Present findings contradict previous findings for e.g. Joshi and Gupta (2010) found no sig differences between the social adjustment level of hostellers and boarders. The probable reason behind the present finding may be the fact that students residing in hostels have many opportunities to develop social adjustment skills in comparison to the day scholars. In hostels, adolescents must develop how to interact with other hostellers and adapt to the changing situations accordingly. The probable reason behind the fact that present findings contradict Joshi \& Gupta (2010) may be the presence of some moderating variable like personality of participants or their early learning environments.

No significant differences were found between day scholars and hostellers in terms of emotional adjustment which implies that type of schooling didn't have an effect on emotional adjustment of adolescents. Present findings support previous findings (Sharma, 2007).

No significant differences were found between day scholars and hostellers in terms of educational adjustment which implies that type of schooling didn't have an effect on educational adjustment of adolescents. The present findings contradict a previous study conducted by Joshi \& Gupta (2010) who found hostellers to be better educationally adjusted than day-scholars. The probable reason behind this finding may be the fact that both institutes (both residential and non-residential) taken in present study had similar educational status; both of them equally competent in imparting good education. May be due to the aforesaid reason, the investigator didn't find any significant difference in the educational adjustment among day-scholars and hostellers.

No significant differences were found between day scholars and hostellers in terms of emotional control which implies that type of schooling didn't have an effect on emotional control of adolescents. The present findings support previous research (Vijayalakshmi, Bhartia \& Muthuvel, 2008)

'In the present study, type of schooling significantly affected perceived loneliness of adolescents. Hostellers were found to experience more perceived loneliness in comparison to the day scholars. Present findings support previous findings (Shah et al., 2009; Wright, 1967).

(C) 2014 www.ijip.in
July-September 2014

143 | P a g e 


\section{The International Journal of Indian Psychology: Volume: 01 | Issue: 04 | ISSN 2348-5396}

No significant differences were found between males and females in terms of total adjustment which implies that gender of participants didn't have an effect on total adjustment of adolescents. The present findings support previous research (Goyat, 2012; Sharma 2012).

No significant differences were found between males and females in terms of home adjustment which implies that gender of participants didn't have an effect on home adjustment of adolescents. The present findings support previous research (Pathak, 1970).

No significant differences were found between males and females in terms of health adjustment which implies that gender of participants didn't have an effect on health adjustment of adolescents. The present findings support previous research (Raju, Rani\& Ramesh, 2009).

In the present study, gender significantly affected social adjustment of adolescents. Females were found to be better socially adjusted in comparison to males. Present findings are consistent with previous findings (Dhillon $\&$ D’ Souza 1992)

No significant differences were found between males and females in terms of emotional adjustment which implies that gender of participants didn't have an effect on emotional adjustment of adolescents. The present findings support previous research (Sharma, 2012; Jdaitawi, Ishak \& Mustafa, 2011).

No significant differences were found between males and females in terms of educational adjustment which implies that gender of participants didn't have an effect on educational adjustment of adolescents. The present findings support previous research (Jdaitawi, Ishak \& Mustafa, 2011).

No significant differences were found between males and females in terms of emotional control which implies that gender of participants didn't have an effect on emotional control of adolescents. The present findings are consistent with previous research (Pant and Prakash, 2004).

No significant differences were found between males and females in terms of perceived loneliness which implies that gender of participants didn't have an effect on perceived loneliness of adolescents. The present findings are consistent with previous research (Archibald, Bartholomew, \& Marx, 1995; Berg \& Peplau, 1982),

When interaction effects were seen between type of schooling and gender on adjustment (total and all five dimensions), no significant interaction effect was found for total, home, emotional and educational adjustment. Similar results have been reported in previous research examining adjustment problems of adolescents that the interaction effect of type of schooling and gender were insignificant (Kakkar, 1967).

The interaction effect of type of schooling and gender on health adjustment was found to be significant. This finding may be explained as both: type of schooling and gender individually are affecting health adjustment among adolescents; thus their interaction has also become significant.

The interaction effect of type of schooling and gender on social adjustment was found to be significant contradicting Joshi \& Gupta (2010) which found the interaction between aforementioned variables to be nonsignificant. This contradiction can be explained on the ground that as type of schooling had a highly significant effect on social adjustment and gender also seemed to affect it in present study, the interaction effect of type of schooling and gender has also been significant. 


\section{The International Journal of Indian Psychology: Volume: 01 | Issue: 04 | ISSN 2348-5396}

Very few researchers have focused on the interaction of type of schooling and gender on emotional control and perceived loneliness up to the knowledge of investigator. However, in the present study, no significant interaction effects have been observed between type of schooling and gender on emotional control. Significant interaction of type of schooling and gender was seen on perceived loneliness. This may be explained as type of schooling has emerged as a highly significant factor in affecting perceived loneliness in spite of the fact that gender is not individually affecting perceived loneliness. So, simply being male or female does not appear to affect perceived loneliness in present study but being in a hostel and being a male or female is affecting it more.

\section{Limitations and suggestions:}

\section{Limitations:}

Although the study was done with sincerity, still it has some limitations which should be taken into account. First of all, the sample was relatively small. Secondly, the study took place at two different schools only which may also affect the generalize ability to other institutions. Consequently, the results will only be applicable to similar institutions in similar settings. Third, the study does not take into account factors like faculty characteristics, teaching styles, overall which could have an effect on student's type of schooling. Fourth, the study took place at one point in time which again limits the ability to generalize the findings to other time periods and replicate the findings. Fifth, the small sample size. Besides these limitations, some other practical problems were also created while data collection. Such problems included lack of cooperation by all students approached for administration of the study, half-filled questionnaires, etc. The questionnaires which were half completed had to be excluded in the final data. There may be a possibility of the presence of moderating variables which might have affected present findings .Better parameters can be set and modifications can be made for overcoming these limitations keeping these problems in mind in the future works.

\section{Suggestions}

Since this study has certain weak points, more controlled studies should be conducted. Such study may be replicated on a regional or a national basis. The sample should be larger and more diverse to improve the generalize ability of the findings. Higher statistics should be used and there should be a better controlled study. There should be consideration of moderating variables and on controlling them. Further research should be conducted on other aspects important for day scholars and hostellers

\section{References:}

1. Abdullah, M.C. (2009).Adjustment among first year students in Malayasian Universities. European Journal of Social Sciences. B, 3/496.

2. Archibald, F.S., Bartholomew, K., \& Marx, R. (1995). Loneliness in early adolescence: A test of the cognitive discrepancy model of loneliness. Personality and Social Psychology Bulletin, 21,296-301.

3. Asher, S. R., Hymel, S., \& Renshaw, P. (1984).Loneliness in children. Child Development,55, 1456-1464.

4. Asher, S. R., \& Wheeler, V. (1985). Children's loneliness: A comparison of rejected and neglected peer status. Journal of Consulting and Clinical Psychology, 53, 500-505.

5. Ayers, T. S., Sandler, I. N., West, S. G., \& Roosa, M. W. (1996). A dispositional and situational assessment of children's coping: Testing alternative models of coping. Journal of Personality, 64(4), 923 958.

6. Barge, J. A., \& Williams, L. E. (2007).The no conscious regulation of emotion. In J. J. Gross (Ed.), Handbook of Emotion Regulation (pp. 429-445). New York: The Guilford Press.

7. Buch, M.B. (Ed) (1991). Survey of research in education, New Delhi: NCERT.

8. Belsky,J (1981). Early human experience: A family perspective. Developmental Psychology,17,3-33.

9. Bell,R. (1981). Worlds of Friendship. Beverly Hills, CA: Sage. 


\section{The International Journal of Indian Psychology: Volume: 01 | Issue: 04 | ISSN 2348-5396}

10. Boivin, M., \&Hymel,S. (1997). Peer experiences and social self-perceptions: Asequential model. Developmental Psychology, 33, 135-145.

11. Boivin, M., Pulin, F., \& Vitaro, F. (1994).Depressed mood and peer rejection in childhood. Development and Psychopathology, 6, 483-498.

12. Brennan,T. (1982). Loneliness at Adolescence. In L. A. Peplau and D. Perlman (Eds.), Loneliness: A sourcebook of current theory, research and therapy (pp. 269-290).New York: Wiley-Interscience.

13. Bradley, S. J. (2000). Affect regulation and the development of psychopathology.

14. Beauchaine, T. P., Gatzke-Kopp, L., \& Mead, H. K. (2007).Polyvagal theory and developmental psychopathology: Emotion deregulation and conduct problems from preschool toadolescence. Biological Psychology, 74, 174-184.New York: Guilford Press.

15. Calkins, S. D., \& Dedmon, S. A. (2000).Physiological and behavioral regulation in two-year-old children with aggressive/destructive behavior problems. Journal of Abnormal Child Psychology, 28, 103-118.

16. Calkins, S. D., \& Fox, N. A. (2002). Self-regulatory processes in early personality development: A multilevel approach to the study of childhood social withdrawal and aggression. Development and Psychopathology, 14, 477-498.

17. Crick, N.R, \& Ladd, G. W. (1993). Children's perceptions oftheir peer experiences:Attributions, loneliness, social anxiety, and social avoidance. Developmental Psychology,29, 244-254.

18. Cotterell,J. (1996). Social networks and social influences in adolescence.London Routledge.Larson, R W., \& Csikszentmihalyi, M. (1980).The significance oftime alone inadolescent development.Journal of Current Adolescent Medicine, 2, 33-40.

19. Calkins, S. D. (1994). Origins and outcomes of individual differences in emotional regulation. InN. A. Fox (Ed.), Emotion regulation: Behavioural and biological considerations, Monographs ofThe Society for Research in Child Development (Vol. 59, Issue 2-3, Series 240). Chicago, Ill:University of Chicago Press.

20. Cole, D. A., \& Turner, E. (1993). Models of cognitive mediation and moderation in child depression.Journal of Abnormal Psychology, 102(2), 271-281.

21. Cole, P. M, Michel, M. K., \& Teti, L. O. (1994). The development of emotion regulation anddysregulation: A clinical perspective. Monographs of the Society for Research in ChildDevelopment, 59 (Serial No. 240), 73-100.

22. Compas, B. E., Connor-Smith, J. K., Saltzman, H., Thomsen, A. H., \& Wadsworth, M. E. (2001). Coping with stress during childhood and adolescence: Problems, progress, and potential in theory and research.Psychological Bulletin, 127(1), 87-127.

23. Campos, J. J., Mumme, D., Kermoian, R., \& Campos, R. (1994).A functionalist perspective on the nature of emotion. In N. A. Fox (Ed.), Emotion regulation: Behavioral and biological considerations, Monographs of the Society for Research in Child Development (pp. 284-303). Chicago, Ill: University of Chicago Press.

24. Cassidy,J., \& Asher, S. R (1992). Loneliness and peer relations in younger children.Child Development, 63,350-365.

25. Calkins, S. D., Fox, N. A., \& Marshall, T. R. (1996).Behavioral and physiological antecedents of inhibition in infancy.Child Development, 67, 523-540.

26. Cicchetti, D., \&Toth, L. (1997).The development of depression in children and adolescents.American Psychologist, 53(2), 221-241.

27. Davidson, R. J., \& Irwin, W. (1999).The functional neuroanatomy of emotion and affective style.Trends in Cognitive Sciences, 3, 11-21.

28. Dhillon. P.K, D’ Souza. S (1992).Psycho-social aspects of aging in India. Concept Publishing, Company New Delhi.

29. Donaldson, J. \& Watson, R. 1996. Loneliness in elderly people: an important area for nursing research. Journal of Advanced Nursing. 24(5), 952-959.

30. Diamond, A. (1991). Young children's performance on a task sensitive to the memory functions of the medial temporal lobe in adults: The delayed nonmatching-to-sample task reveals problems that are due to non-memory-related task demands. Behavioral Neuroscience, 108, 659-680. 


\section{The International Journal of Indian Psychology: Volume: 01 | Issue: 04 | ISSN 2348-5396}

31. Durbin, E. C. \& Shafir, D. M. (2007).Emotion regulation and risk for depression.InAbela, J. R. Z. \&Hankin, B. L. (Eds.), Handbook of depression in children and adolescents (149-176). New York: Guildford Press.

32. Epkins, C. C. (1998). Mother- and father-rated competence, child-perceived competence, and cognitive distortions: Unique relations with children's depressive symptoms. Journal of Clinical Child Psychology, 27(4), 442-451.

33. Fox, N. A. (1994). Dynamic cerebral process underlying emotion regulation. In N. A. Fox (Ed.),Emotion regulation: Behavioral and biological considerations, Monographs of the Society forResearch in Child Development. Chicago, Ill: University of Chicago Press.

34. Fox, N. A., Henderson, H. A., \& Marshall, P. J. (2001).The biology of temperament: An integrative approach. In C. A. Nelson \& M. Luciana (Eds.), The Handbook of Developmental Cognitive Neuroscience (pp. 631-646). Cambridge, MA: MIT Press.

35. Fox, H. C., Axelrod, S. R., Paliwal, P., Sleeper, J., \& Sinha, R. (2007).Difficulties in emotionregulation and impulse control during cocaine abstinence.Drug and Alcohol Dependence, 89, 298-301.

36. Fernandez-Berrocal, P., Alcaide, R., Extremera, N., \& Pizarro, D. (2006).The role of emotionalintelligence in anxiety and depression among adolescents.Individual Differences Research,4, 16-27.

37. Gray, J. A. (1994). Three fundamental emotion systems. In P. Ekman \& R. J. Davidson (Eds.), The Nature of Emotion: Fundamental Questions (pp. 243-247). New York: OxfordUniversity Press.

38. Good, C.V. (1959). Dictionary of education, (P: 6). New York: McGraw -Hill Book Company.Gross (Ed.), Handbook of Emotion Regulation (pp. 87-109). New York: Guilford Press.

39. Gottlieb, G. (1991). Epigenetic systems view of human development. Developmental Psychology, 27, 3334.

40. Goyet, A (2012).A Study of adjustment level among primary school teachers in jhajjardirstrict.International journal of transformations in business management.1(6).

41. Gross, J. J. (1999). Emotion regulation: past, present, future. Cognition and Emotion 13, 551-573.

42. Gross, J. J., \& Thompson, R.A. (2007). Emotion Regulation: Conceptual Foundations. In J. J. Gross (Ed.), Handbook of Emotion Regulation (pp. 429-445). New York: The Guilford Press.

43. Gross, J. J. (1998). The emerging field of emotion regulation: An integrative review. Review ofGeneral Psychology, 2, 271-299.

44. Gross, J. J. (1998). Antecedent- and response-focused emotion regulation: divergent consequences for experience, expression, and physiology. Journal of Personality andSocial Psychology, 74(1), 224-237.

45. Grolnick, W., Cosgrove, T., \&Bridges, L. (1996). Age-graded change in the initiation of positive affect. Infant Behavior and Development, 19, 153-157.

46. Garnefski, N., Kraaij, V., \& van Etten, M. (2005).Specificity of relations between adolescents'cognitive emotion regulation strategies and internalizing and externalizing psychopathology.Journal of Adolescence, 28, 619-631.

47. Gratz, K. L., \& Roemer, L. (2004). Multidimensional assessment of emotion regulation anddysregulation: Development, factor structure, and initial validation of the Difficulties inEmotion Regulation Scale. Journal of Psychopathology and Behavioral Assessment, 26, 4154.

48. Gratz, K. L., Tull, M. T., Baruch, D. E., Bornovalova, M. A., \& Lejuez, C. W. (2008). Factorsassociated with co-occurring borderline personality disorder among inner-city substanceusers: The roles of childhood maltreatment, negative affect intensity/reactivity, and emotiondysregulation. Comprehensive Psychiatry,49, 603-615.

49. Gratz, K. L., \& Roemer, L. (2008). The relationship between emotion dysregulation and deliberate selfharm among female undergraduate students at an urban commuter university. Cognitive Behaviour Therapy, 37, 14-25.

50. Gratz, K. L., Paulson, A., Jakupcak, M., \& Tull, M. T. (2009).Exploring the relationship between childhood maltreatment and intimate partner abuse: Gender differences in the mediating role of emotion dysregulation. Violence and Victims, 24, 68-82. 


\section{The International Journal of Indian Psychology: Volume: 01 | Issue: 04 | ISSN 2348-5396}

51. Gratz, K. L., Rosenthal, M. Z., Tull, M. T., Lejuez, C. W., \& Gunderson, J. G. (2006).Anexperimental investigation of emotion dysregulation in borderline personality disorder.Journal of Abnormal Psychology, $115,850-855$.

52. Gottman,1. M., \& Parker, 1. (1986). The conversations offriends: Speculations on affective development. New York: Cambridge University Press.

53. Gratz, K. L., \& Roemer, L. (2004). Multidimensional assessment of emotion regulation anddysregulation: Development, factor structure, and initial validation of the Difficulties inEmotion Regulation Scale. Journal of Psychopathology and Behavioral Assessment, 26, 4154.

54. Goswick, R.A, \& Jones, W. H. (1981).Loneliness, self-concept, and adjustment.Journal of Psychology, 107,237-240.

55. Garnefski, N., Kraaij, V., \&Spinhoven, P. (2002). CERQ: Manual for the use of the cognitive emotion regulation questionnaire. Leiderdorp, Netherlands: DATEC.

56. Horowitz,L. M., French, R.\& Anderson, C. A (1982). The prototypes ofalonelyperson. In L.A Peplau \& D. Perlman (Eds.), Loneliness: A sourcebook of current theory, research and therapy (p. 263).New York: Wiley-Interscience,

57. Hymel, S., Rubin,K. H., Towden, L., \& Lemare, L. (1990). Children's peer relationships:Longitudinal predictionof internalizing and externalizing problems from middle to late childhood. Child Development, 61, 2004-2021.

58. Inderbitzen-Pisaruk, H., Clark, M. L.\& Solano, C. H. (1992). Correlates ofloneliness inmidadolescence.Journal of youth and Adolescence, 21, 151-167.

59. Johnson, K. A., Zvolensky, M. J., Marshall, E. C., Gonzalez, A., Abrams, K., \&Vujanovic, A. A. (2008).Linkages between cigarette smoking outcome expectancies and negative emotionalvulnerability.AddictiveBehaviors, 33, 1416-1424.

60. Joshi,R\& Gupta, M.,(2010).Adjustment and Personality Pattern among Boarders and Day Scholars Adolescents. International ResearchJournal.,13(II),42-46.

61. Jdaitawi, M.T, Ishak, N.A, Mustafa, T.F.(2011). Emotional Intelligence in modifying social and academicadjustment among first year university student in north Jordan.International journal of psychological studies.3(2) 103-141.

62. Kochenderfer,B. 1., \& Ladd, G. W. (1996). Peer victimization: Cause or consequence ofschool mal ad justment? Child Development, 67, 1293-1305.

63. Kulshrestha, S.P. (1979). Educational psychology. Meerut, India: Loyal Book Depot.

64. Killeen, C. 1998. Loneliness: an epidemic in modern society. Journal of Advanced

65. Nursing.28(4), 762-770.

66. Koenig, L. J., \&Abrams, R (1999). Adolescent loneliness and adjustment: A focus on older differences. InK.Rotenberg.Childhood and adolescent loneliness301-303). Cambridge, England: Cambridge University Press.

67. Karnick, P. 2005. Feeling lonely: Theoretical perspectives.Nursing Science Quarterly. 18(1), 7-12.

68. Kopp, C. (2002). Commentary: The co-developments of attention and emotion regulation. Infancy, 2,199208.

69. Kopp, C. (1982). Antecedents of self-regulation: A developmental perspective. Developmental Psychology, $18,199-214$.

70. Kupersmidt, J. B., Voelger, ,M. E., Sigda, K. B., \&Sedikides, C. (1999). Social self-discrepancy theory and 10neliness during childhood and adolescence.In K. Rotenberg, Childhood and adolescen loneliness (pp. 263-279). Cambridge, England: Cambridge University Press.

71. Lengua, L. J. (2002). The contribution of emotionality and self-regulation to the understanding of children's responses to multiple risks.Child Development, 73, 144-161.

72. Ladd,G. W., Kochenderfer, B. J., \& Coleman, C. C. (1996). Friendship quality as apredictorof young children's early school adjustment.Child Development, 67, 1103-1118.

73. Lazarus, R. S. (1991). Cognition and motivation in emotion.American Psychologist, 46, 352-367. 


\section{The International Journal of Indian Psychology: Volume: 01 | Issue: 04 | ISSN 2348-5396}

74. Ladouceur, C. D., Dahl, R. E., Williamson, D. E., Birmaher, B., Ryan, N. D., \& Casey, B. J. (2005). Altered Emotional Processing in Pediatric Anxiety, Depression, and Comorbid Anxiety-Depression.Journal of Abnormal Child Psychology, 33(2), 165-177.

75. Leitenberg, H., Yost, L. W., \& Carroll-Wilson, M. (1984). Negative cognitive errors in children: Questionnaire development, normative data, and comparisons between children with and without selfreported symptoms of depression, low self-esteem, and evaluation anxiety. Journal of Consulting and Clinical Psychology, 54(4), 528-536.

76. Lang, P. J., Bradley, M. M., \& Cuthbert, B. N. (1990). Emotion, attention, and the startle reflex.Psychological Review, 97, 377-395.

77. Lane, R. D., \& Schwartz, E. (1987). Levels of emotional awareness: A cognitive-developmental theory and its application to psychopathology. American Journal of Psychiatry, 144(2), 133-143.

78. Luebbers, S., Downey, L. A., \&Stough, C. (2007). The development of an adolescent mEI. Personality and Individual Differences, 42, 999-1009.

79. Mahmondi, A. (2010).Influence gender on adjustment among adolescent.Journal of Social Science Research. 2:53 - 64.

80. Monroe, P. (ed.) (1990). International encyclopedia of education. New Delhi: Cosmo Publications.

81. Moore, D.,\& Schultz, N. R (1983). Loneliness at adolescence: Correlates, attributions, andcoping.Journal of Youth and Adolescence, 12, 95-100.

82. Marcoen, A, \& Goossen, L. (1987).Loneliness in pre-through late adolescence.In K. Rotenberg, Childhood and adolescent loneliness (p. 334). Cambridge, England:Cambridge University Press.

83. Mohsin, S.M. \&Hussain, S. (1985).Mohsin - Shamshad Hindi adaptation of Bell adjustment Inventory (student form).Patna: Acrovoice.

84. Ochsner, K. N., \& Gross, J. J. (2005).The cognitive control of emotion.Trends in CognitiveSciences, 9(5), 242-249.

85. Ochsner, K. N., \& Gross, J. J. (2007).The neural architecture of emotion regulation.In J. J.

86. Ostrov,E., \& Offer, D. (1978). Loneliness and the adolescent.In S. Feinstein (Ed.), Adolescent Psychology. Chicago: University of Chicago Press.

87. Pant, N., and Prakash, A. (2004), Multifactor emotional intelligence scale in India: An evaluation. Psychological studies, 49,128-135.

88. Pettigrew, S. \& Roberts, M. 2008.Addressing loneliness in later life.Aging \& Mental Health. 12(3), 302309.

89. Petrides, K. V., Frederickson, N., \&Furnham, A. (2004).The role of trait emotional intelligence in academic performance and deviant behavior at school.Personality and Individual Differences, 36, 277-293.

90. Peplau, L.A., \& Perlman, D. (Eds.) (1982). Loneliness: A sourcebook ofcurrent theory, research and therapy.New York: Wiley-Interscience.

91. Parkhurst,1. T.,\& Asher, S. R (1992). Peer rejection in middle school: Subgroup differences in behavior, loneliness and interpersonal concerns. Developmental Psychology, 28,231-241.

92. Perveen, S. \&kazmi S.F (2011).Personality dynamics of boarders and day scholars who belong to madrassa and public school. Academic Research in International Journal,1(1) 157-172.

93. Perlman, D. (1991).Age difference in Loneliness: A meta-analysis. Vancouver, BritishColumbia, Canada: University of British Columbia.

94. Parker,1. G., \& Asher, S. R (1993). Friendship and friendship quality in middlechildhood: Links with peer group acceptance and feelings ofloneliness and social dissatisfaction.DevelopmentalPsychology, 29, 611621.

95. Penza-Clyve, S., \& Zeman, J. (2002).Initial validation of the Emotion Expression Scale for Children (EESC).Journal of Clinical Child and Adolescent Psychology, 31(4), 540-547.

96. Pathak, R.D., 1970, Sex differences among school children in the areas of adjustment. Psych. Studies, 15 : 120-122. 


\section{The International Journal of Indian Psychology: Volume: 01 | Issue: 04 | ISSN 2348-5396}

97. Rydell, A., Berlin, L., \& Bohlin, G. (2003).Emotionality, emotion regulation, and adaptation among 5- to 8year-old children.Emotion, 3(1), 30-47.

98. Rothbart, M. K., Ahadi, S. A., \& Evans, D. E. (2000). Temperament and personality: Origins and outcomes. Journal of Personality and Social Psychology, 78(1), 122-135.

99. Rothbart, M. K., Derryberry, D., \& Hershey, K. (2000). Stability of temperament in childhood: Laboratory infant assessment to parent report at seven years. In V. J. Molfese\& D. L. Molfese(Eds.), Temperament and personality development across the life span (pp. 85-119). Mahwah, NJ: Erlbaum.

100. Rafaelli, M., \& Duckett, E. (1989).Conversations in early adolescence.JournalofYouth and Adolescence, $18,567-582$

101. Rubin, K H., \& Mills, R. S. L. (1991).Conceptualizing developmental pathways tointernalizing disorders in childhood.Canadian Journal of Behavioural Science,23, (3), 300-317.

102. Rothbart, M. K. (1989). Temperament and development.In G. Kohnstamm, J. Bates, \& M. K. Rothbart Eds.), Temperament in childhood (pp. 187-248). Chichester, England: Wiley.

103. Rothbart, M. K. (1981). Measurement of temperament in infancy. Child Development, 52, 569-578.

104. Rothbart, M. K. (1986). Longitudinal observation of infant temperament. Developmental Psychology, 22, 356-365.

105. Rotenberg,K 1. (1995). The socialization of trust : Parents' and children's interpersonaltrust. International Journal of Behavioural Development, 18, 713-726.

106. Rubin,K H., Chen, x., \& Hymel, S. (1993). Socioemotional characteristics of withdrawn and aggressive children. Merrill-Palmer Quarterly, 39, 518-534.

107. Russell, D., Peplau, L.A, \& Cutrona, D. E. (1980). The revised UCLA loneliness scale:Concurrent and discriminant validity evidence.Journal of Personality and Social Psychology,39, 472-480.

108. Roy, B., Ekka, A., \& Ara, A. (2010).Adjustment among university students.Journal for Social Development.Vol 2. (2), ISDR.Ranchi.

109. Rokach, A., Matalon, R., Rokach, B. \&Safarov, A. 2007.The effects of gender and marital status on loneliness of the aged.SocialBehavior and Personality. 35(2), 243-254.

110. Rook, K. 1984.Research on social support, loneliness and social isolation towards an integrated review of personality.In Donaldson, J. \& Watson, R. 1996. Loneliness in elderly people: an important area for nursing research. Journal of Advanced Nursing. 24 (5), 953.

111. Ruff, H., \& Rothbart, M. K. (1996). Attention in early development. New York: Oxford University Press.

112. Raju, M.V.R \& Rahamtullah, K. (2007).Adjustment problems among school children.Journal of the Indian Academy of Applied Psychology.33 (1), 73 - 79.

113. Raju, T.J.M.S. Rani,T.I, Ramesh, D.(2009).Health Psychology and Counselling. Discovery Publishing House PVT.LTD.

114. Roemer, L., Lee, J. K., Salters-Pedneault, K., Erisman, S. M., Orsillo, S. M., \&Mennin, D. S.(2009). Mindfulness and emotion regulation difficulties in generalized anxiety disorder:Preliminary evidence for independent and overlapping contributions. Behavior Therapy, 40,142-154.

115. Rotenberg,K (1999). Childhood and adolescent loneliness (p.5). Cambridge, England:Cambridge University Press.

116. Silk, J. S., Steinberg, L., \& Morris, A. S. (2003). Adolescents' emotion regulation in daily life: Links to depressive symptoms and problem behavior. Child Development, 74(6), 1869-1880.

117. Schneirla, T. C. (1959). An evolutionary and developmental theory of biphasic processes underlying approach and withdrawal. In M. Jones (Ed.), Nebraska Symposium on Motivation (Vol. 7, pp. 1-42). Lincoln: University of Nebraska Press.

118. Stifter, C. A., \& Moyer, D. (1991). The regulation of positive affect: Gaze aversion activity during motherinfant interaction. Infant Behavior and Development, 14(1), 111-123.

119. Sippola,L., \&Bukowski, W. M. (1999). The Uniquely deve10pmental focus of thechildhood and adolescent literature.In K Rotenberg, Childhood and Adolescent Loneliness(p.344). Cambridge, England: Cambridge University Press 


\section{The International Journal of Indian Psychology: Volume: 01 | Issue: 04 | ISSN 2348-5396}

120. Salters-Pedneault, K., Roemer, L., Tull, M., Rucker, L., \&Mennin, D. S. (2006). Evidence of broad deficits in emotion regulation associated with chronic worry and generalized anxietydisorder. Cognitive Therapy and Research, 30, 469-480.

121. Salovey, P., Mayer, J. D., Goldman, S. L., Turvey, C., \&Palfai, T. P. (1995). Emotional attention, clarity, and repair: Exploring emotional intelligence using the trait meta-mood scale. In J. W. Pennebaker (Ed.), Emotion, disclosure, and health (pp. 125-154). Washington, DC:American Psychological Association.

122. Shah, C. ,Trivedi, R.S., Diwan J , Dixit R , Anand A K. (2009). CommanStrosserAndCoping OF Stress By Medical Student ,Journal of Clinical and Diagnostic Research, 3,1621-1626

123. Sullivan, H.S. (1953). The interpersonal theory ofpsychiatry. New York: Norton.

124. Southam-Gerow, M. A., \& Kendall, C. (2002). Emotion regulation and understanding: Implications for child psychopathology and therapy. Clinical Psychology Review, 22(2), 189-222.

125. Southam-Gerow, M. A., \& Kendall, P. (2001).Emotion regulation and understanding implications for child psychopathology and therapy.Clinical Psychology Review, 22, 189-222.

126. Savikko, N. 2008.Loneliness of older people and elements of an intervention for its alleviation.AnnalesUniversitatisTurkuensis.Nro 808.Turunyliopisto.Hoitotieteenlaitos.Doctoral thesis.

127. Shields, A., Cicchetti, D., \& Ryan, R. M. (1994).The development of emotional and behavioralselfregulation and social competence among maltreated school-age children. Developmentand Psychopathology, 6, 57-75.

128. Sharma, R. (2007). Influence ofmodernization and gender onadjustment level of adolescentsof government and privateschools. Behavioural Scientist Vol. 8 (2), 81-88.

129. Shrama,R.(2012). Ego strength in relation to adjustment of college -going student.Indian streams research journal.2(1)1-4.

130. Thompson, R. A. (1994). Emotion regulation: A theme in search of definition. In N. A. Fox (Ed.), The development of emotion regulation. Monographs of the Society for Research in Child Development, 59, $25-52$.

131. Thompson, R. A. (1994). Emotion regulation: A theme in search of definition. In N. A. Fox (Ed.), The development of emotion regulation: Biological and behavioral considerations, Monographs of the Society for Research in Child Development, 59(2/3, Serial No. 240), 25-52. Chicago, Ill.

132. Tull, M. T., Barrett, H. M., McMillan, E. S., \& Roemer, L. (2007).A preliminary investigation of the relationship between emotion regulation difficulties and posttraumatic stress symptoms.Behavior Therapy, 38, 303-313.

133. Tull, M. T., \& Roemer, L. (2007). Emotion regulation difficulties associated with the experience of uncued panic attacks: Evidence of experiential avoidance, emotional nonacceptance, anddecreased emotional clarity. Behaviour Therapy, 38, 378-391.

134. Tull, M. T., \& Gratz, K. L. (2008). Further examination of the relationship between anxietysensitivity and depression: The mediating role of experiential avoidance and difficultiesengaging in goal-directed behavior when distressed. Journal of Anxiety Disorders, 22, 199210.

135. Tems, C. L., Stewart, S. M., Skinner, J. R., Hughes, C. W., \& et al,. (1993). Cognitive distortions in depressed children and adolescents: Are they state dependent or traitlike? Journal of Clinical Child Psychology, 22(3), 316-326.

136. Vijayalekshmi,VBhartia, A \& Muthuvel, R. (2008).Emotional Intelligence and Social Reticence of PostGraduate female student.Journal of the Indian Academy of applied psychology.34(1)93-100.

137. Wright JJ.(1967) Reported personal stress sources and adjustment of entering freshmen. Journal of Counseling Psychology 1967; 14(4):371-373.

138. Younger, J. 1995. The alienation of the sufferer.Advances in Nursing Science. 17(4), 53-72. Read 1.3.2011.

139. Zeman, J., Cassano, M., Perry-Parrish, \& Stegall, S. (2006). Emotion regulation in children andadolescents.Developmental and BehavioralPediatrics, 27, 155-168.

140. Zeman, J., Shipman, K., \& Suveg, C. (2002). Anger and sadness regulation: Predictions to internalizing and externalizing symptoms in children. Journal of Clinical Child and Adolescent Psychology, 31(3), 393-398. 